\title{
ARQUITETURA DE NORMAN FOSTER
}

Valquiria Amaral, Bárbara Moraes, Luiz Santos, Korina Aparecida Teixeira Ferreira da Costa

Universidade do Oeste Paulista, Curso de Arquitetura e Urbanismo, Presidente Prudente, SP. E-mail: valkiriamaral@hotmail.com.

\section{RESUMO}

O presente artigo tem como objetivo discorrer sobre as diferentes formas de manifestação da tecnologia seja como concepção arquitetônica ou pela própria arquitetura contemporânea. Para isso, lançou-se mão de três obras do arquiteto Norman Foster, escolhidas pela forma como foram concebidas e desenvolvidas, buscando assim contextualizá-las ao início da tendência High-Tech, detalhando em cada obra, as suas características e soluções aplicadas. Como resultado da pesquisa foi possível obter em uma análise mais profunda, quanto esse arquiteto e suas obras influenciaram a atualidade. Concluímos que ele, nessa iniciativa de obras High-Tech veio a ser o precursor de uma arquitetura limpa, em verdadeira simbiose com o meio ambiente.

Palavras-chave: Concepção arquitetônica - tecnologia - projeto - sustentável - energia

\section{FOSTER NORMAN ARCHITECTURE}

\begin{abstract}
This article aims to discuss the different manifestations of technology is as architectural design or by the contemporary architecture. For this, he employed three works of Norman Foster architect, chosen by the way they were designed and developed, thus seeking to contextualize them at the beginning of high-tech trend, detailing in each work, its characteristics and applied solutions. As a result of research it was possible to get into a deeper analysis, as this architect and his works influenced the present. We conclude that it, this initiative of High-Tech works became the precursor of a clean architecture, in true symbiosis with the environment.
\end{abstract}

Keywords: Architectural design - technology - project - sustainable - energy 


\section{INTRODUÇÃO}

O mundo passa por uma crise no abastecimento de petróleo na década de 1970, e vultosas somas são gastas nas pesquisas de energia alternativa, visando compensar o problema vivido na época. A utilização de estrutura em aço e concreto era uma técnica muito empregada entre as décadas de 1960 e 1970, um nicho na arquitetura mundial. Alemanha, Espanha e Japão estimulam a fabricação em escala de células voltaicas à base de silício, gerando energia elétrica a partir de luz solar.

A partir de tal época, o Tardo-modernismo propunha a utilização da tecnologia contemporânea dando continuidade à utilização de métodos e renovações de processos. (Castelnou 2015, apud Raja1986). A nova tendência da arquitetura destaca a produção de espaços construídos em harmonia com o meio ambiente, ou seja, menos impacto ambiental, redução do consumo de energia e preservação de recursos não renováveis, do Eco-tech.

O High-Tech, abreviatura de high technology, ocorreu, como tendência arquitetônica, a partir dos anos 70 e se constituiu em uma utilização de métodos, figuras, tecnologia e materiais da arquitetura e engenharia industriais em programas comerciais e residenciais urbanos. Caracteriza-se pela exposição dos sistemas técnicos (elétricos. hidráulicos, climatização, circulação), uso intenso de cores vivas e acabamentos metálicos, vedações com painéis industrializados e vidro, nunca com processos tradicionais de alvenaria, por exemplo, grandes vãos e estruturas tensionadas. Esta exposição dos sistemas técnicos foi chamada, jocosamente, de poética do intestinismo. (COLIN, 2000, SP)

Em 1987 a ministra da Noruega baseada no relatório "Our Common Future" elaborado por Gro Harlem Brundtland, ressalta na Assembléia da ONU, que o empobrecimento da população é a principal causa dos problemas ambientais no mundo e que "desenvolvimento sustentável" seria a nova concepção de crescimento econômico aliado à preocupação ecológica.

O objetivo deste artigo é o de esmiuçar as diferentes formas de expressão tecnológicas, aplicadas à arquitetura, buscando o menor impacto possível com a natureza, zelando assim pelo meio ambiente, demonstrando através das principais obras de Norman e das características de seus contemporâneos.

\section{METODOLOGIA}

A metodologia basea-se numa investigação bibliográfica e se fundamentará numa abordagem qualitativa de pesquisa, utilizando-se como instrumento um levantamento bibliográfico e documental, que segundo Teixeira (2000, p. 137), busca a correlação entre a teoria 
e os dados, entre o contexto e a ação, a partir da compreensão dos fenômenos por meio de sua descrição e interpretação. Para o trabalho com o estudo do tipo de levantamento bibliográfico ocorrerá inicialmente um levantamento das principais produções no contexto nacional de estudos, considerando a peculiaridade do objeto de estudo.

Desse modo, percebe-se que a pesquisa qualitativa vale-se do método indutivo, segundo o qual parte da observação, da análise dos fatos particulares, dos registros para compor um quadro compreensivo para então constituir a generalização universal, ou seja, a teoria. O processo de indução vale-se do princípio do empirismo, no qual o conhecer é dar significado à realidade (KÖCHE, 1997, p. 62).

\section{NORMAN FOSTER}

A maneira encontrada para avaliar as diversas formas de manifestação, aliadas à tecnologia, foi a de resumir historicamente os principais arquitetos e seus feitos, levantando assim subsídios para a análise dos resultados finais. Através do gosto pela criação pura e em sintonia com a virada cultural dos anos 80 e 90 se destacam através de extraordinário trabalho os arquitetos Richard Rogers, Renzo Piano, Jean Nouvel e Norman Foster.

Richard Rogers produz obras com simplificação formal progressiva e de versátil adequação aos lugares e instrumentos tecnológicos. Renzo Piano, já possui formação humanística e um singular talento de origem tecnológica. Jean Nouvel, arquiteto francês que respeita em seus projetos a referência aos lugares e o empenho tecnológico, prefere trabalhar em lugares históricos e assim participar da evolução da cidade.

Norman Foster, arquiteto inglês possui um sucesso extraordinário, e constrói uma linguagem pessoal fortemente reconhecível. A partir de uma visão ímpar do lugar, com crítica radical ao conceito de tipologia, nasce uma reelaboração profunda do lugar avaliado e com isso há um forte respeito ao movimento e fluxo das pessoas dentro dos edifícios.

Segundo Foster "virtualmente tudo o que é construído pelo homem, passou por um processo projetual que implica escolhas e decisões", isso significa que a arquitetura não está confinada a um campo específico de ação, mas que cada ato humano de transformação é arquitetura. (FOSTER, 2000, p.453). Surge então um espaço isomorfo e multifuncional, onde o movimento, a luz natural e a transparência tornam-se bases para seus projetos.

Foster nasceu em Manchester no ano de 1935. Em 1953 após seus estudos superiores, ingressa na RAF - Royal Air Force como engenheiro eletrônico, apesar de já possuir uma formação, 
demonstrou interesse por arquitetura, principalmente pelas obras de Ludwig Mies van der Rohe, Frank Lloyd Wright e Le Corbusier.

Em 1961 gradua-se como arquiteto pela Universidade de Manchester. Conclui seu mestrado na Universidade de Yale onde conhece seu futuro sócio e parceiro comercial, Richard Rogers. Seguidor dos conceitos de James Stirling, Foster defende a tendência do pós-modernismo na arquitetura, tornando-se um dos arquitetos mais influente e prestigiado de nossa atualidade.

Em 1967 ele une-se a Wendy Cheesman, fundando a Foster Associates, futuramente denominada Foster and Partners com sede em Londres, reconhecida mundialmente por suas obras pelo mundo, principalmente na Europa. Sua empresa acumula 190 prêmios e foi vitoriosa em mais de 50 competições internacionais. No ano de 1999 recebe o Premio Pritzker da Fundação Hyatt, também conhecido como o Nobel da arquitetura.

Existe uma grande variedade de obras famosas as quais os projetos são de sua autoria, eis algumas delas: 1986 - Torre do HSBC (Hong kong- China); 2002 - 8 Canada Square (Londres Reino Unido); 2002 - Prefeitura de Londres (Londres - Reino Unido); 2004 - Viaduto de Millau (Milau - França); 2004 - 30 St Mary Axe (Londres - Reino Unido); 2006 - Torre Hearst (Nova Yorque - USA).

\section{EDIFÍCIO 30 ST MARY AXE}

Conhecido como "The Gherkin", possui cento e oitenta metros de altura, quarenta e um andares, com $47.000 \mathrm{~m}^{2}$, ocupado com escritórios, restaurante e bar, projetado no ano de 2001 e construção finalizada em 2004.

Localizado em Londres onde se tornou um marco para a cidade, é facilmente identificado no skyline londrino pela sua forma exótica de ogiva e por estar em ponto estratégico na famosa cidade inglesa fornecendo aos privilegiados uma visão panorâmica de todo o centro financeiro da cidade é o sexto mais alto prédio da região metropolitana de Londres.

Após dez anos de sua construção recebeu o prêmio máximo do conselho que regula a construção e o desempenho de edifícios na capital inglesa. O prêmio avalia desde a concepção estética, quanto às vantagens de ventilação natural, qualidade de espaços públicos e flexibilidade de usos.

O prédio possui em sua base $49 \mathrm{~m}$ de diâmetro, na parte mais larga mede $56,5 \mathrm{~m}$ e se estreita para 26,5 no último andar, o que the confere o formato oval, the dando o apelido de pepino, mas na visão de seu criador tais características favorecem a ventilação, diminui a pressão 
sobre a estrutura. Foi implantado em terreno estreito, seguiu todas as exigências com muita precisão aos sistemas energéticos e de iluminação natural.

Com esquema tradicional de uma torre, tem grande hall de entrada, espaço especial no topo e uma praça pública na frente ou ao redor, localiza-se entre as ruas St. Mary Axe e Bury Street, onde anteriormente havia sido alvo de atentado do Irã, em função desse fato o térreo do edifício é destinado ao comércio.

A principal preocupação de Foster para projetar o edifício era a ventilação natural e a iluminação, obtidas através de aberturas para o exterior. A forma circular foi recortada de maneira que as reentrâncias resultantes do desenho fossem aproveitadas para a instalação de átrios periféricos para melhor incidência de luz e criação de jardins, a disposição entre os andares sofre uma diferença espacial de cinco graus, fornecendo assim um átrio espiral por onde corre uma ventilação vertical, e farta claridade.

A estrutura do edifício é composta por um núcleo central contornado por uma grelha em espiral formada por elementos de aço interconectados diagonalmente. O sistema portante da torre conta com uma armadura exterior de aço construída com duas peças em formato $V$ invertidas; ao todo são 19 anéis superpostos em forma de losango. Os painéis da fachada têm tripla espessura, vidro duplo na parte externa com filme e um vidro interno laminado, cuja preocupação é de controlar a penetração da luz natural sem interferir na vista para a cidade.

A estrutura é composta por mais de cinco mil e quinhentos painéis metálicos, mas apenas os situados nos átrios podem ser abertos, o prédio foi programado para reduzir em $40 \%$ ao ano o uso de condicionadores de ar; as peças pré-fabricadas foram feitas na Holanda e Bélgica.

Os escritórios possuem uma disposição ortogonal, no entanto os elevadores, banheiros e escadas são retangulares, a maior parte das salas possui vista para a paisagem, e somente $3 \%$ das salas são fechadas, normalmente salas de reuniões. O edifício foi palco de vários filmes como Harry Potter e o Enigma do Príncipe, Match Point e outros.

\section{CITY HALL}

Localizado as margens do Rio Tâmisa, na região de Southbank, região que abriga prédios novos e revitalizados com valor cultural, turístico e arquitetônico, o City Hall é o primeiro de 12 edifícios a ser desenvolvidos pela equipe da Foster.

O edifício abriga a câmara e o gabinete do prefeito de Londres. É um modelo de democracia, acessibilidade e sustentabilidade com um formato de esfera inclinada, fatiada e 
transparente compostas por panos de vidro. Sua construção aconteceu de 1998 a 2002; possui cinquenta metros de altura.

O projeto privilegia espaços ao ar livre, e uso da população, sempre buscando valorizar a vista do rio, as estruturas e serviços da região. Possui um anfiteatro abaixo do nível da rua com acesso ao edifício de dez pavimentos. No subsolo, existe uma cafeteria e um amplo espaço de exposições, a luz natural é refletida pelo forro em forma de elipses concêntricas. Uma rampa parte do subsolo em forma de espiral que conduz a todos os pavimentos, até a cobertura. No segundo piso localiza a Assembleia e uma rampa leva a um mezanino que permite a visualização da paisagem do rio através de panos de vidro triangulares.

A paisagem vista através da rampa é maravilhosa, no entanto a melhor vista é proporcionada da sala de estar. Localizada no topo do edifício e aberta ao público, o local é usado para exposições ou recepção de até 200 pessoas, o terraço circunda todo o ambiente e oferece visão panorâmica do entorno. A implantação do City Hall visava à economia de energia, e seu desenho deriva de uma esfera geometricamente modificada, conseguindo um melhor aproveitamento de espaço em menor área; fica no sentido norte sul aproveitando assim uma maior incidência de luz solar com a fachada voltada para o sul. O desenho é fatiado criando assim áreas sombreadas na fachada.

Sua estrutura é feita em aço e concreto reforçado, cada painel que compõe a fachada tem formato e dimensões únicas, com cálculos específicos, as placas de vidro são cortadas a laser garantindo alto grau de segurança.

\section{HEARST TOWER}

Localizado na esquina da Eighth Avenuee 57th Street em Nova Yorque, EUA é um exemplo de inovação tecnológica, por ser o primeiro arranha-céu de Manhattan que recebeu a medalha de ouro do programa Leadership in Energy and Environmental Design (LEED, em inglês Liderança em Energia e Projetos Ambientais).

A torre possui cento e oitenta e dois metros de altura, com quarenta e seis andares. A construção ocorreu de 2003 a 2006, possuindo $80.000 \mathrm{~m}^{2}$ e sua fachada retrata o formato de diamante. No ano de 2008 o arquiteto Norman Foster recebeu o prêmio International Highrise Awar em Frankfurt na Alemanha, pelo projeto da torre, que elevada sobre um imóvel antigo com arquitetura ArtDeco de 1928, preservando apenas a fachada da estrutura já existente que serviram de grande lobby do novo prédio e estabelecendo assim um diálogo criativo entre o velho 
e o novo. A antiga estrutura é ligada a nova através de painéis de vidro que inundam de luz natural os espaços internos, gerando uma leveza visual e dando a impressão que a torre flutua.

A Hearst Tower não é uma arquitetura convencional, sua estrutura é composta por um sistema denominado diagrid (grade diagonal), trata-se de uma malha diagonal que usa 20\% menos aço do que uma armação convencional, resultando em uma economia de 2.000 toneladas do material. Sua fachada é composta por peças diagonais que além da função decorativa ou de vedação, compõem o sistema estrutural, trata-se de um formato muito semelhante ao do diamante, enfatiza as proporções verticais e cria uma silhueta ímpar proporcionando um skyline diferenciado a Manhattan. Os 46 andares consomem 25\% menos energia que um prédio comum e $80 \%$ da estrutura original demolida foram reutilizadas. De todo o aço utilizado na construção, $90 \%$ refere-se a aço reciclado.

Um gramado no telhado coleta a água das chuvas que é reutilizada no próprio edifício, na rega das plantas internas ou da rua, e também na queda d'água que tem a função de umidificar o ambiente térreo. Buscando economia e conforto fez-se uso de automação da luz que foi estudada de maneira aprofundada. Nos escritórios tem sensores que controlam a quantidade de luz nos pavimentos de acordo com a incidência de luz solar, também detectam a utilização dos computadores, e quando estão sem atividade são desligados automaticamente.

A base da torre de Artdeco é caracterizada por sua estrutura com colunas e estátuas retratando alegorias da musica, arte, comércio e indústria. A praça e o átrio no piso térreo permite acesso a todas as outras partes do edifício, ladeado por um auditório, tudo contrastando a tranquilidade do átrio com a agitação da rua.

O projeto inclui um acesso para a estação de metro local, com entrada no interior do edifício, dando aos funcionários acesso direto ao transporte público.

Em nossa análise detectamos que na maioria de suas obras, o consumo de energia é cerca de 20 a $25 \%$ menor que em outro edifício convencional e ainda, $80 \%$ da estrutura desenhada acaba sendo executada com material reciclado. Por mais alto ou amplo que seja o projeto, a principal preocupação é a redução no consumo de energia, seja para manter o edifício refrigerado e iluminado, ou seja para elevá-lo com um consumo racional de materiais, preservando assim as fontes naturais de materiais.

\section{CONSIDERAÇÕES FINAIS}

Norman Foster é um renomado arquiteto inglês reconhecido mundialmente por seu estilo ousado e pela preocupação com o meio ambiente e uso da tecnologia. 
Suas obras são emblemáticas, sempre com tecnologia inovadoras, caracterizadas pelo high tech que faz o arquiteto ousar em seus projetos com sistemas construtivos semelhantes aos adotados em indústrias, mas com forte preocupação com o meio ambiente.

A contribuição dos seus projetos para o mundo é transformadora, pois renovaram diversas cidades, sistemas de transportes, e todos sendo baseados principalmente em conceitos conscientes com o meio ambiente, valorizando a ecologia como fator principal.

A característica principal de suas obras está na utilização de tecnologias inovadoras presentes na indústria pesada, adotadas como soluções e preservadoras do meio ambiente. Faz uso normalmente de estruturas metálicas, vidros, soluções sustentáveis e muito diálogo com o lugar que se está inserida a obra.

Percebe-se claramente que a cada projeto cria-se um desafio em como elevá-lo ao menor custo com melhor segurança e qualidade. Buscando essas metas, o arquiteto lança mão de inúmeras alternativas para que o conforto e a praticidade do ambiente, não percam sua magnitude.

\section{REFERÊNCIAS}

BENEVOLO, Leonardo. A arquitetura no novo milênio. São Paulo, Estação Liberdade, 2007.

NESBIT, Kate. Uma nova agenda para Arquitetura. Cosac Naify,2008.

SÃO PAULO, (Folha). Norman Foster. Coleção Folha Grandes Arquitetos, vol 7.

RAJA, R. Arquitetura pós-industrial. São Paulo: Perspectiva, 1986.

COLIN, Sílvio. Uma introdução à Arquitetura. Rio de Janeiro: Uape, 2000.

KÖCHE, J. C. Fundamentos de metodologia científica: teoria da ciência e iniciação à pesquisa. 22. ed. São Paulo: Vozes, 2004.

TEIXEIRA, E. As três metodologias. 2a . ed. São Paulo: Vozes, 2000. 